\title{
Research Perspectives on Children of Divorce: Introduction
}

$\mathrm{I}^{\mathrm{n}}$ nvestigation into the potential effects of divorce on the trajectory of child development is less than two decades old. Initially, the relatively low incidence of legally granted divorces in the general population of most Western countries resulted in studies of children whose parents had never married or cases in which a husband deserted his family (the so-called poor man's divorce). Thus, the primary focus was, of necessity, on economically disadvantaged segments of the population. Reflecting the political and moral climate of the times, pre-1960s reports characterized these youngsters as the troubled products of "broken homes."

Studies of children whose parents had been granted a divorce by the courts began to find their way into the published research literature in substantial numbers during the 1960s via the emphasis then on the effects of father absence on personality development. The increase in the divorce rate in the middle class made such research possible. But during that decade most studies did not distinguish divorce from other life circumstances that were associated with "father absence." Divorce, death, and prolonged unavailability of fathers due to their occupation or military service often were lumped together under the same rubric.

It was not until the early 1970s that the study of divorce and its possible effects on children was differentiated from the conglomerate of life experiences represented in the father absence literature. The pioneering work of Wallerstein and Kelly ushered in the current era of research on children of divorce. As their published reports were issued during the mid-1970s, and with the increasing recognition of the dramatic rise in the divorce rate between 1965 and 1975 , investigators from the fields of developmental and clinical psychology, sociology, social work, psychiatry, law, and education began to focus their efforts on divorce and the children involved.

Reports about children of divorce have proliferated during the 1980 s. The rigor of social science research methods and the indepth, sensitive methods of clinical investigation were brought to bear on this topic. New insights have been won through these efforts. The significant extent of disruption in child development for the majority of youngsters during the initial stage of parental separation now has been elaborated and widely agreed upon. And the enduring legacy of divorce, for a substantial minority of children, has also been documented by several investigators, though the actual percentage of youngsters adversely affected in the long run is still an unresolved question.

The early, and necessary, broad-gauged studies, aimed at answering the questions of whether or not divorce affects children negatively and what the nature of the negative sequelae are, have begun to give way, to a great extent, to attempts to understand what specifically about divorce is stressful to children in the short as well as long run. These new avenues of research have naturally led to explorations of the factors that contribute to children's successful, healthy

At the invitation of the Editor, this special section was initiated by Neil Kalter during his recent term of service on the Editorial Board of this Journal. 
adaptation to divorce. These recent thrusts carry significant implications for preventive interventions and clinical services as well as for important social policy issues.

$\mathrm{T}$ his special section is too small to represent adequately the range of research currently in the literature regarding children of divorce. Its contents were selected using three guiding criteria. First, to be included in this section, a paper had to have clear clinical or social policy relevance. Second, a paper had to meet the requirement of being both methodologically and conceptually sophisticated. Finally, the collection of papers had to represent diversity with respect to methods of inquiry and theoretical position. Taken together, these criteria represent the history, traditions, and values of the American Journal of Orthopsychiatry.

The paper by Camara and Resnick continues Camara's decade-long efforts to apply the methods and conceptual frameworks of developmental psychology to understanding postdivorce family dynamics and their effects on child development. The authors, using structural family theory, separate the roles of ex-spouse and coparent. By doing so, they demonstrate that the frequently employed concept of "interparental hostility," as a contributing factor to children's postdivorce difficulties, is too global and needs to be refined. Their findings suggest that clinicians' efforts to help children of divorce could be enhanced by facilitating the postdivorce relationship and helping divorced parents achieve effective styles of conflict resolution within their roles as coparents. This is notably different from trying to aid parents in resolving their continued hostilities as ex-spouses. Their data indicate that it is possible, and perhaps likely, for ex-spousal hostilities to continue while still achieving a workable, effective coparenting relationship that serves children's developmental needs well.

The paper by Johnston, Kline, and Tschann has important implications for so- cial policy as well as for counseling or mediation efforts with highly conflicted divorcing couples. Drawing on her rigorous training as a social scientist (in sociology), and simultaneously making use of coded clinical interview data, Johnston and her colleagues present the most careful study to date of custody type and its effects on children's well-being within the context of embattled divorces. The issue of joint versus sole custody has been hotly and widely debated for nearly a decade, but rarely studied using a longitudinal design, standardized measures, and clinical interviews. The findings presented here are particularly important because they address precisely the population of divorcing couples, and their children, that clinicians are asked to evaluate and courts must make decisions about regarding child custody. (The authors correctly advise readers not to generalize their results to circumstances where couples freely agree to joint custody.) That joint custody can work well for some divorced couples, and benefit their children, does not mean that this arrangement works well when it is imposed. When they point to the important role of the coparental relationship in postdivorce child adjustment, one is very much reminded of the findings reported by Camara and Resnick.

Wallerstein and Corbin examine the adjustment of females at the ten-year point after parental divorce. They use in-depth clinical methods, rigorously applied by experienced clinicians, that have been the hallmark of the research reported by Wallerstein and her colleagues. Wallerstein and Corbin's findings underscore the need for long-range, longitudinal research in assessing the impact of divorce on girls. Though earlier reports of the California Children of Divorce Project indicated that girls adapted to parental divorce more readily and more effectively than did their male peers, a finding widely replicated by others who have studied the short-term effects of divorce, Wallerstein and Corbin's paper points to serious long-term effects of divorce for a 
sizable subgroup of girls. Because these difficulties only emerge in adolescence and young adulthood, Wallerstein and Corbin call them "sleeper" effects. While their findings are especially important for practicing clinicians, they also shed light on our understanding of the powerful effects postdivorce vicissitudes can have on female development. Specifically, the girl's identification with her divorced mother and her internalization of her parents' relationship appears to shape in important ways an adolescent girl's and young woman's experience of herself, especially within the context of an intimate relationship.

In my own work, which concludes the section, my colleagues and I attempt a simultaneous test of several key hypotheses we distilled from the children of divorce literature. These hypotheses have been put forth by investigators over these two decades of research on children of divorce to explain how and why divorce affects child development. We were especially interested in determining how much of the considerable variation in children's levels of postdivorce adjustment could be accounted for by each of these hypotheses. In past research, these theories regarding the mechanisms through which the divorce experience exerts differential effects on youngsters have been addressed piecemeal so that the comparative weight of each could not be determined. Our findings, though preliminary and based on a relatively small, local sample, suggest that the postdivorce emotional adjustment of the custodial parent be given considerably more weight than has been the case to date. For the boys in our sample, who on the average appeared somewhat more beset by emotional difficulties than boys generally, and for the girls in our sample, who were as well adjusted as girls generally, variation in emotional wellbeing was linked to custodial parents' own personal adjustment. The implications for preventive and traditional clinical services aimed at helping children adjust successfully to divorce are clear: more emphasis may need to be placed on helping custodial parents cope well with divorce so that they may then be better equipped to buffer their youngsters from ongoing, divorce-related stresses in the long run.

The papers in this section represent stateof-the-art research on centrally important issues regarding children of divorce. Collectively, they underscore the value of bringing to bear diverse methods of investigation and different theoretical perspectives on significant matters facing our society. It is through this multidisciplinary, multimethod approach, inherent in the Journal's zeitgeist, that we are in a better position to broaden and deepen our understanding of children of divorce.

Neil Kalter, Ph.D. Director, Center for the Child and the Family University of Michigan Ann Arbor 